\title{
Resenha histórica da Revista da Faculdade de Direito da UFRGS: criação, objetivos e desenvolvimento
}

\author{
Carlos Silveira Noronha*
}

Na oportunidade em que assumimos, por delegação do Senhor Diretor desta Faculdade de Direito, Professor Plínio de Oliveira Corrêa, a Direção da Revista da Faculdade, julgamo-nos no dever de registrar em suas páginas, a criação, os objetivos e a atuação desse prestigiado periódico nestes cinquienta e quatro anos de sua caminhada histórica.

A gênese do surgimento da Revista da Faculdade de Direito deve ser tributada a duas deliberações acadêmicas tomadas pela Congregação, ligadas a acontecimentos que permearam o final da década de 49 e o alvorecer da década de 50 . O primeiro dizia respeito às homenagens que seriam prestadas pela Faculdade por ocasião do centenário do nascimento de Ruy Barbosa, em 05 de novembro de 1949; o segundo teve como pedra de toque os preparativos para comemorar o cinqüentenário de fundação da Faculdade de Direito, em 17 de fevereiro de 1950.

Assim, a 18 de março de 1947, como retrata a Ata $n^{\circ} 301$, reunia-se a Congregação da Faculdade, durante a gestão do Professor Elpídio Ferreira Paes (1942/1948), para tratar, entre outros assuntos, dos preparativos para homenagear o centenário do nascimento de Ruy Barbosa, contando com as presenças dos Professores João Bunumá, Francisco José Simch Junior, Vicente Marques Santiago, Amadeu Fagundes de Oliveira Freitas, Oswaldo Caminha, Armando Dias de Azevedo, José Salgado Martins, Hernani Estrella e Dario Bittencourt. Nesta sessão da Congregação, foi deliberada a

\footnotetext{
* Professor Titular, Doutor em Direito. Diretor da Revista da Faculdade de Direito da Universidade Federal do Rio Grande do Sul (UFRGS), nomeado pela Portaria $n^{\circ}$ 24/2002-FD, da Direção da Faculdade.
} 
abertura de inscrições dos Professores para a elaboração de trabalhos jurídicos especiais a serem publicados em homenagem ao centenário do nascimento de Ruy Barbosa. E, na sessão extraordinária da Congregação, realizada em 05 de agosto de 1949 (Ata ${ }^{\circ}$ 310), durante a primeira gestão do Professor José Salgado Martins (1948/1951), quando eram discutidas as comemorações do cinquientenário da Faculdade, foi aprovada uma proposição do Professor Edgar Luiz Schneider, convidando os Professores a escrever e publicar obras jurídicas pertinentes ao evento, a comemorar-se em 17 de fevereiro de 1950.

Com a realização desses trabalhos jurídicos para comemorar as duas efemérides mencionadas, estavam lançados os fatores genéticos para a fundação de um órgão destinado a publicar as produções acadêmico-científicas dos corpos docente, administrativo e discente da Faculdade de Direito. E tal ocorreu na primeira gestão e por iniciativa do Professor José Salgado Martins (1948/1951), quando, em 1949, era editado o primeiro número da Revista da Faculdade, contendo dezessete artigos de doutrina, somando 268 páginas, de autoria de Osvaldo Aranha, Borges de Medeiros, Aparício Mendez, João Amorim de Albuquerque, Elpídio Ferreira Paes, Orlando da Cunha Carlos, Darcy Azambuja, José Salgado Martins, Ruy Cirne Lima, Hernani Estrella, Edgar Luiz Schneider, Armando Dias de Azevedo, Amadeu de Oliveira Freitas, Paulo Barbosa Lessa, Paulo Brossard de Souza Pinto, Luís Lopes Palmeiro e Werter Faria. Naquela oportunidade era Reitor da Universidade o Professor Alexandre Martins da Rosa.

Nascia, assim, o periódico, fundado na aspiração dos seus criadores de oferecer a esta Unidade de Ensino universitário um veículo de divulgação da cultura jurídica e das demais atividades acadêmicas que se expandiam nas salas de aula, na Sala dos Professores e nos gabinetes, com a determinação de institucionalizá-las no âmbito da Faculdade de Direito. Essa edição comemorativa foi realizada sob as vistas diligentes de uma Comissão de Redação e Revisão constituída pelos Professores Darcy Azambuja, Ruy Cirne Lima e Edgar Luiz Schneider, tendo como Secretário de Redação o Doutor Paulo Brossard de Souza Pinto.

Seguiram-se as edições publicadas no ano de 1951, que levaram os números 2, 3 e 4, sob a regência da mesma Comissão de Redação e Revisão e do mesmo Secretário de Redação anteriormente mencionados, quando ainda exerciam a Reitoria da Universidade e a Direção da Faculdade de Direito, os Professores Alexandre Martins da Rosa e José Salgado Martins, respectivamente.

A partir daí, por razões desconhecidas, a Revista deixou de ser publicada por cerca de vinte anos, ressurgindo no ano de 1971, quando veio a lume o 
número 5. Nessa oportunidade, assumiu o encargo de Diretor do periódico o Professor Elpídio Ferreira Paes, a Comissão de Redação e Revisão ficando constituída pelos Professores Clóvis Veríssimo do Couto e Silva, João Pedro dos Santos e Lenine Nequete, quando a Reitoria da Universidade era exercida pelo Professor Eduardo Zacaro Faraco e a Direção da Faculdade pelo Professor José Salgado Martins, em sua terceira gestão.

No ano de 1972, foi publicado o volume número 6 da Revista, quando a Direção do periódico estava cometida ao Professor Érico Maciel Filho, mantida a mesma Comissão de Redação e Revisão da edição anterior, exercendo, na época, a Reitoria da Universidade, o Professor Ivo Wolf, e Diretor e Vice-Diretor da Faculdade os Professores José Salgado Martins e Francisco José Simch.

Durante os anos de 1973/1974, surgiu mais uma edição da Revista, na qual foram condensados os números 7 e 8 , sob as mesmas direções da Reitoria e da Faculdade de Direito mencionadas acima, quando figurava como Diretor da Revista o Professor Lenine Nequete e a Comissão de Redação e Revisão constituída pelos Professores Elmo Pilla Ribeiro e Clóvis Veríssimo do Couto e Silva.

No período de 1974 a 1992, a Revista deixou de circular por mais dezenove anos, voltando a ser publicada a partir de 1993, continuadamente, sob a Direção do Professor Franz August Gernot Lippert, que a exerceu no período de 1993 a 2002, quando foram editados os números $9,10,11,12,13$ $14,15,16,17,18,19,20,21$ e 22 . Os números 9 e 10 foram publicados um em cada ano, em 1993 e em 1994; os números 11 e 12 foram ambos editados durante o ano de 1996; os números 13 e 14, condensados em um só volume, publicados em 1997; o número 15, em 1998; os números 16 e 17, durante o ano de 1999; o número 18, no ano de 2000; o número 19, no ano de 2001; e os números 20, 21 e 22, foram todos publicados durante o ano de 2002. Nas oportunidades das publicações dos números 9 a 11, exerciam a Reitoria da Universidade o Professor Hélgio Trindade, a Direção da Faculdade o Professor Peter Walter Ashton e a Vice-Direção o Professor Ivo Sefton de Azevedo; quando da publicação do número 12, era a Reitoria da Universidade exercida pela Professora Wrana Maria Panizzi, sendo Diretor e Vice-Diretor da Faculdade os mesmos dois Professores por último mencionados; a partir das edições dos números 13-14, 15, 16, 17 e 18, continuavam a Reitoria da Universidade a ser exercida pela Professora Wrana Maria Panizzi, sendo a Direção da Faculdade de Direito desempenhada pelo Professor Eduardo Kroeff Machado Carrion e a Vice-Direção pelo Professor Plínio de Oliveira Corrêa; nas publicações dos números 19, 20, 21 e 22, 
permanecia como Reitora da Universidade a Professora Wrana Maria Panizzi, sendo Diretor da Faculdade o Professor Plínio de Oliveira Corrêa e Vice-Diretor o Professor Sérgio José Porto.

Durante o ano de 1999, surgiu uma edição especial da Revista, comemorativa dos 50 anos da Lei Fundamental da República Federal da Alemanha, com tradução de Peter Neumann e apresentação do Professor Paulo Bonavides, sem numeração de volume, sob os auspícios do Programa de PósGraduação em Direito da Faculdade; e, durante o ano de 2002, foram publicadas mais duas edições especiais, uma, no mês de agosto desse ano, em homenagem à Cooperação entre a Universidade do Texas-Austin (EE.UU.) e a UFRGS; a outra, em homenagem à Cooperação entre a Faculdade de Direito da Universidade de Tohoku, Sendai-Japão e a Faculdade de Direito da UFRGS, todas sob a Direção do Professor Franz August Gernot Lippert e mediante a organização da Professora Cláudia Lima Marques, da UFRGS. Também estas duas últimas não tiveram seus volumes numerados.

A partir da edição do número 15, no ano de 1998 e até a publicação do número 22 e das três ultimas edições especiais, constituiu-se um Conselho Editorial da Revista, do qual participaram os Professores Blásio Hugo Hickmann, Carlos Alberto Alvaro de Oliveira, Carlos Freire Hofmeister, Carlos Silveira Noronha, Cezar Saldanha Souza Jr., Cláudia Lima Marques, Cláudio Michelon Jr., Eduardo K. M. Carrion, Franz August Gernot Lippert, Galeno Vellinho de Lacerda, José Sperb Sanseverino, Juarez Freitas, Judith Martins-Costa, Luís Afonso Heck, Luiz Fernando Barzotto, Odone Sanguiné, Peter Walter Ashton, Rui Portanova, Sérgio José Porto, Vera Maria Jacob de Fradera e o acadêmico Felipe Madsen Etges.

Com a Portaria ${ }^{\circ}$ 24/2002-FD, de 06 de agosto de 2002 e mais recentemente com a Portaria $N^{\circ}$ 014/2003, de 04.09.2003, foi oficialmente designado o atual Conselho Editorial da Revista, constituído pelos ex-diretores, professores titulares, professores doutores, servidores técnico-administrativos e acadêmicos de direito, como segue: Pelos ex-diretores: Galeno Vellinho de Lacerda, Almiro Régis do Couto e Silva, José Sperb Sanseverino, Peter Walter Ashton e Eduardo Kroef Machado Carrion; pelos professores titulares: Carlos Alberto Alvaro de Oliveira, Carlos Silveira Noronha, Cezar Saldanha Souza Jr., Cláudia Lima Marques e Sérgio José Porto; pelos professores doutores: Carlos Freire Hofmeister, Cláudio Fortunato Michelon Jr., Juarez Freitas, Judith Martins-Costa, Luis Afonso Heck, Luiz Fernando Barzotto, Odone Sanguiné, Rui Portanova, Vera Maria Jacob de Fradera; pelos servidores técnicos-Administrativos: jornalista Blásio Hugo Hickmann e a bibliotecaria-chefe, bel. Naila Touguinha Lomando; e a aca- 
dêmica Ana Paula Zavarize Carvalhal, pelo Centro Acadêmico André da Rocha (CAAR).

Figuram também como assessores, membros-técnicos da Direção da Revista, o professor Blásio Hugo Hickmann, como jornalista-responsável pela edição e a bacharel em Biblioteconomia, Naila Touguinha Lomando, responsável técnica pela revisão e adequação do texto às normas da ABNT.

Esperando dar continuidade ao relevante papel que a Revista vem até aqui desempenhando, na senda de divulgar as atividades acadêmico-científicas desenvolvidas nesta Instituição de ensino do Direito, permitimo-nos convidar a todos os professores, acadêmicos e servidores técnico-administrativos a emprestarem sua colaboração em prol desta nobre empreitada, que não é de uma pessoa, nem de um grupo, mas dos três corpos que militam nesta centenária Faculdade de Direito.

A Revista tem sua sede no prédio da Faculdade de Direito da Universidade Federal do Rio Grande do Sul (UFRGS), situado na Avenida João Pessoa $n^{\circ}$ 80, Bairro Centro, CEP. 90040-000, Fones/Fax: (51) 3316.3464; 3316.3118; e-mail: diretor@direito.ufrgs.br, na cidade de Porto Alegre, Brasil. 


$$
\text { . }
$$

